\title{
Reducing Private Cars Dependency to Achieve Sustainable Urban Environment in Congested Cities
}

\author{
Mona. M. Adbelhamid ${ }^{1}$, Mohamed. M. Elfakharany ${ }^{1}$ and A. M. Elfakharany ${ }^{2}$ \\ ${ }^{1}$ Lecturer of Architecture, Faculty of Engineering, Pharos University in \\ Alexandria, Alexandria, Egypt \\ ${ }^{2}$ Teaching Assistant of Architecture, Arab Academy for Science, Technology \\ and Maritime Transportm, College of Engineering and Technology, \\ Alexandria, Egypt
}

\begin{abstract}
Using private cars as a main mean of transportation in large cities is usually the preferable solution for their citizens. This dependency on individual private cars is usually due to the absence of other convenient public transportation. Egyptian cities are facing several environmental pollution problems from the crowded roads with the increased number of private cars.

This paper will highlight the harmful impact of private car dependency on the environment and the urban context. Then, it introduces different solution that can help in minimizing the car dependency problem in congested cities. Then it goes for an analysis of the city centre of Copenhagen, which is considered the model of how to transform a large city from car dependent to a friendlier city for cycling and walking. Benefiting from the analysed case study, some solutions could be introduced to the city centre of Alexandria to solve car dependency problem within the urban context of the old town (Safeya Zaghloul Street).
\end{abstract}

\section{Introduction}

Car dependency is defined as high levels of per capita automobile travel, automobile oriented land use patterns, and reduced transport alternatives. [1] Car dependency is a matter of degree; the extreme is when private cars make almost all local trips because other alternatives are inadequate.

Car dependency is considered as huge problem in many urban city centres. This in turn, leads to a serious environmental problem as well as to traffic congestion within the urban context. Policy makers should take a positive action toward avoiding congested street in the city centre rather than just expanding the roads. Providing several options for citizens can solve the car dependency problem such as encouraging walkability and bicycling by improvement pedestrian/bicycle environment. It is also important to enhance the quality of public transportation within the cities.

The main aim of this paper is to highlight some strategies, which could assist planners and urban designers in outlining the problem and suggesting possible solutions to be applied in Alexandria's city centre

\section{Impact of Car Dependency}

Car Dependency has environmental, social and economic impact that may affect negatively the human living environment. 


\subsection{Environmental Impact}

The environmental consequences of transport are the result for infrastructure and the vehicles using this infrastructure, these consequences include visual pollution, air pollution, roads congestion and the depletion of renewable resources. Although automobile and aeroplanes are considered to be more damaging to the environment than other modes of transport, most transport modes result also in some form of negative environmental consequences. [2]

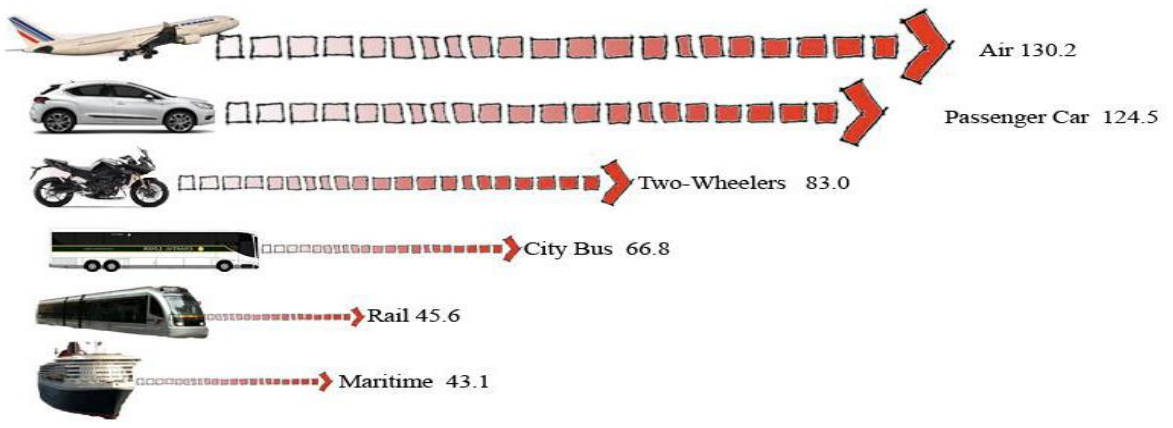

Fig. 1. Co2 emissions per passengers (grams per kilometres), Source: European Environment Agency; Edited by Researcher

\subsection{Social Impact}

Social benefits have been accompanying with the automobile such as independence, freedom as well as the ability to participate in spatially separated activities such as employment, shopping, and recreational activities. However, there are many negative social consequences associated with automobile use such as traffic noise, which cause significant health and social problems. Noise causes cardiovascular diseases, high blood pressure, and insomnia prohibits undisturbed outdoor recreation and damages the learning and reading abilities of school-age children. [3] Canadian and American data shows a theme that aims to turn these cities into activityfriendly environments that are built to serve human; this is by introducing Pedestrian and Cyclists Equity Act, which oppose theautomotive scale, (e.g. building safe routes to schools) and providing incentives for people to become physically more active [4]

Car use is associated with greater health risks that most people are neglecting. It is always associated with road deaths and serious injuries resulting from accidents. Automobile use also affects livability, community life, social interaction and all the aspects related to the human biological and psychological well-being and quality of urban life. Residents on lightly trafficked streets have much more social contacts, more friends and more are socially interactive than residents of heavily trafficked streets. [5]

\subsection{Economic Impact}

"Historically, economic growth and transport growth have gone hand in hand". [6] Automobile cities suffer a number of economic impacts, such as congestion costs in terms of the high costs of urban infrastructure. 


\section{Tackling Car Dependency Problem}

Congestion of the urban context in the city centre streets is mainly created by car dependency as a main type of transportation. Solutions for such a problem can be divided in three phases: the governmental policies, transportation planning policies and the urban design policies.

\begin{tabular}{|c|c|c|}
\hline $\begin{array}{l}\text { Governmental } \\
\text { policies }\end{array}$ & $\begin{array}{l}\text { Transportation } \\
\text { planning policies }\end{array}$ & $\begin{array}{l}\text { Urban design } \\
\text { policies }\end{array}$ \\
\hline $\begin{array}{l}\text { - Car free zones } \\
\text { - Car pooling } \\
\text { - Car sharing } \\
\text { - Parking pricing } \\
\text { - Congestion } \\
\text { charging }\end{array}$ & $\begin{array}{l}\text { Enhancing the } \\
\text { quality of public } \\
\text { transportation }\end{array}$ & $\begin{array}{l}\text { Promoting } \\
\text { physical activity } \\
\text { such as : } \\
\text { walkability and } \\
\text { cycling. }\end{array}$ \\
\hline
\end{tabular}

Fig. 2. Policies applied to minimize car dependency. Source: The researchers

\subsection{Governmental Policies}

\subsubsection{Car-Free Zone Policy (Pedestrian Zones)}

The government should provide pedestrian zones in cities and towns to increase the vitality and attractiveness of their city centers.[7]

\subsubsection{Car Pooling Policy}

Car-pooling means the usage of the private car that belongs to one person in order to carry a number of his colleagues. This solution has many benefits on the city as it reduces parking demand as well as reducing traffic congestion by decreasing the number of vehicle trips on the existing road network and pollution reduction. [8]

\subsubsection{Car Sharing Policy}

Car Sharing can effectively supplement public transport by providing a "car-on call" whenever you need it, eliminating the need for private car ownership. It offers the option for the customer to use the most appropriate vehicle for every trip - from the small city car to medium-sized family cars or even vans and mini-buses. Customers are billed at the end of the month for time and/or mileage. [9]

\subsubsection{Parking Pricing Policy}

The main benefits of this policy is to discouraging the use of private vehicles and encouraging public transport which will lead to a reduction in traffic congestion as well as a reduction of carbon emissions in the environment.[10]

\subsubsection{Congestion Charging Policy}

In this policy, there is a charge taking from motorists using roads during the peak hours of the day. This strategy aims at benefiting the urban transport system as a whole, especially when the collected outcome is reinvested into the local transport system. [11] 


\subsection{Transportation Planning Policies}

\subsubsection{Enhancing the Quality of Public Transport}

The quality of the service provided by the public transpirations should be enhanced In order to encourage citizen to shift from using their private cars to use different types of public transportations. There should be also integration between different modes of public transportation in order to reduce the overall journey time of an individual. [12]

\subsection{Urban Design Policies}

\subsubsection{Walking Strategy}

Walking strategy could be the better solution during the peak hour's car as well as for short distance. This strategy can lead to reduce environmental pollution reduction promoting a healthy living environment. However, there are a number of factors contribute to make walking within the city an inconvenient and unpleasant experience. Between these factors is the conflict with other modes of transport especially vehicles which often leads to pedestrians feeling unsafe and unsecure. The lack of adequate pedestrian facilities as well as the presence of anti-social behaviour, including beggars and illegal street traders, create an unattractive environment and contribute to discouraging walking as a mode of travel

\subsubsection{Cycling Strategy}

Cycling is a totally free of emissions mode of transport, which does not affect the urban atmosphere negatively. Also, cycling is known as the most energy efficient means of transport. [13] Cycling is cost effective this is because the bicycle itself is cheap, the maintenance costs are also reasonable, and the necessary infrastructure is cheap compared to alternative modes. It has also low space requirements. A parked bicycle uses about 1 square meter, less than 8 percent of what a car needs (and even less in the case of two-level bicycle parking). Using the bicycle as a daily means of transport is a convenient and easy way to integrate physical activity in an urban lifestyle. [14] There is basically two ways of combining bicycles and public transport: a) The bicycle can be parked at terminals; and b) The bicycle can be taken on the train/bus as accompanied luggage.

There are four types of bicycles facilities; these types are classified as shown in the following figures:

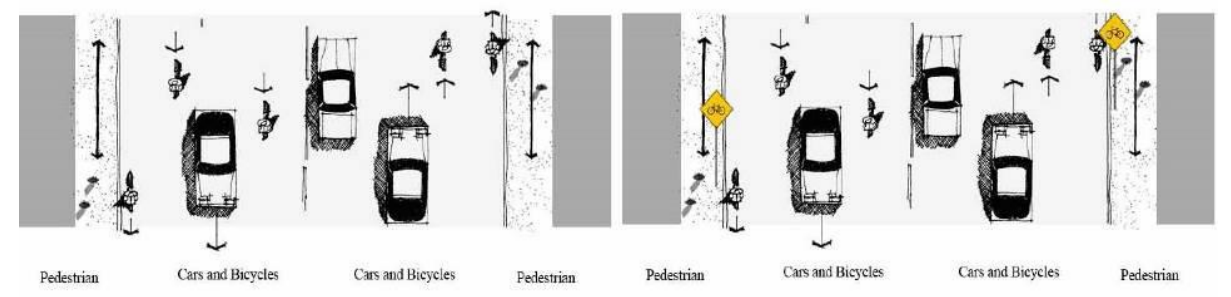

Fig. 3. To the left plan sketch for the shared roadway; to the right plan sketch for the signed shared roadway. Source: The researchers 


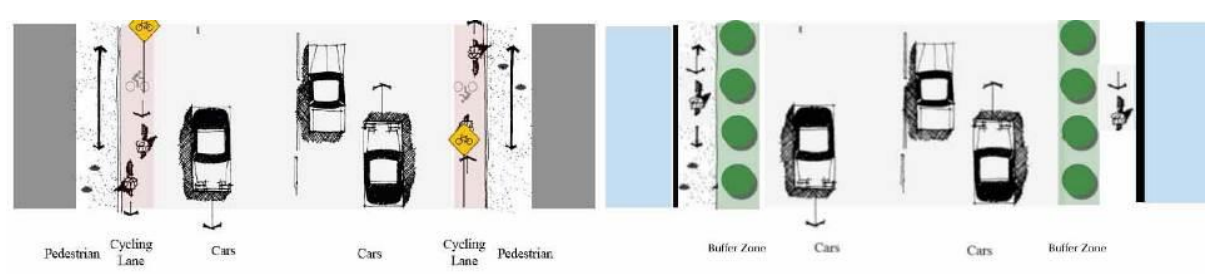

Fig.4. To the left plan sketch for the signed bike lanes; to the right plan sketch for the Shared -Use Path. Source: The researchers

\section{Analytical Example: Copenhagen}

Copenhagen is one of the world's great pedestrian cities. Although it has such a narrow medieval street grid, the city tired to make it's best to improve the quality of its streets. In the last 40 years since Copenhagen's main street was turned into a pedestrian, city planners have taken numerous small steps to transform the city centre from a car dependent city to a people-friendly one. As far back as 1970 a large number of bus priority lanes were introduced and a comprehensive network of segregated cycle paths was built. [15]

\subsection{Governmental Policies:}

Three of the discussed governmental policies have been applied to transform the city streets to a pedestrian-friendly urban context.

\subsubsection{Congestion Charging}

The actual case of Copenhagen is that there is no official policy for the introduction of road pricing. The political debate on road pricing has just started and no solid decision has been taken or approved so far. In 1999, the City Council decided a proposal for a road-pricing scheme to be developed in co-operation with Greater Copenhagen. [16]

\subsubsection{Parking Pricing}

From 1950s, a notable increase in the number of cars in the centre of Copenhagen, this soon filled streets and squares with cars to the point of bursting. In1995, pay parking was introduced in the city centre. While in September 2009, the Copenhagen City Council has renewed the parking strategy. The goal was to establish 4,000 new parking spaces by opening three underground car parking and closing 1,000 on-street parking spaces in the inner city centre before the end of 2014. On-street parking was to be closed for the purpose of improving urban spaces. The policy has now been modified again in the way that on-street parking is to be increased in places where there is a documented need for more parking. [17]

\subsubsection{Car-Free Zones (Pedestrian Zones)}

Copenhagen's City Council decided in 1962 - to establish a car free pedestrian zone from the Westerly Town Hall Square to Kongens Nytorv (The Kings New Square) in the eastern part of the town called "Strøget" 
having a total length of almost3,2 $\mathrm{km}$ - and being the oldest and longest pedestrian street system in the world.
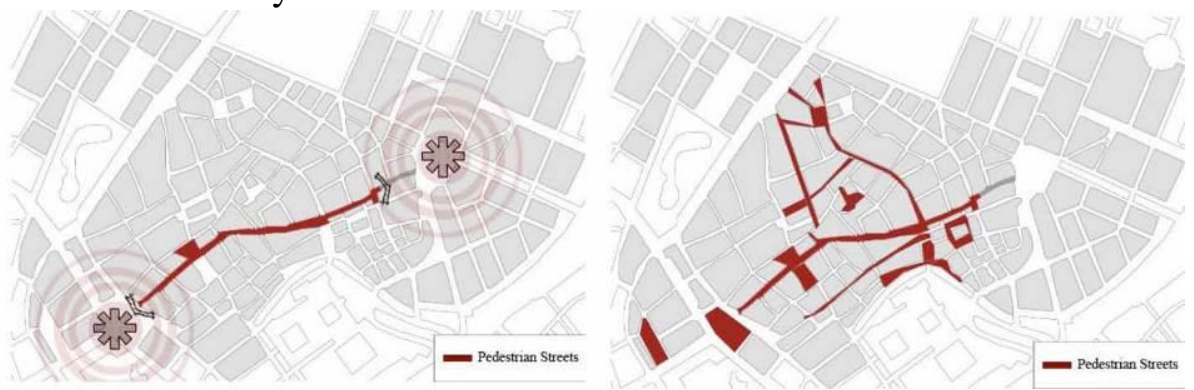

Fig.5 Development of car-free streets and squares in Copenhagen city centre, the left in 1962-96, the right in 2005. Source: (Wallstrom, 2010) ; Edited by Researcher

\subsection{Transportation Planning Policies:}

Traffic increase during the last 10 years in Copenhagen has raised congestion and reduced the average travel speed in the city centre $34 \mathrm{kph}$ to $29 \mathrm{kph}$ during peak hours. In addition to this development, the rush hours are gradually being spread over more and more hours of the day. The viable solution seems to be increased traffic control and travel demand management, combined with improvements in public transport. [16]

This problem has been solved by integrated transport interchanges, which according to Copenhagen city are places where people switch between different modes of transport. They can be railway stations, bus terminals and bus stops. In these interchange nodes you will find movement and quick changes between modes of transport but there is also a need for places to wait and rest. [18]

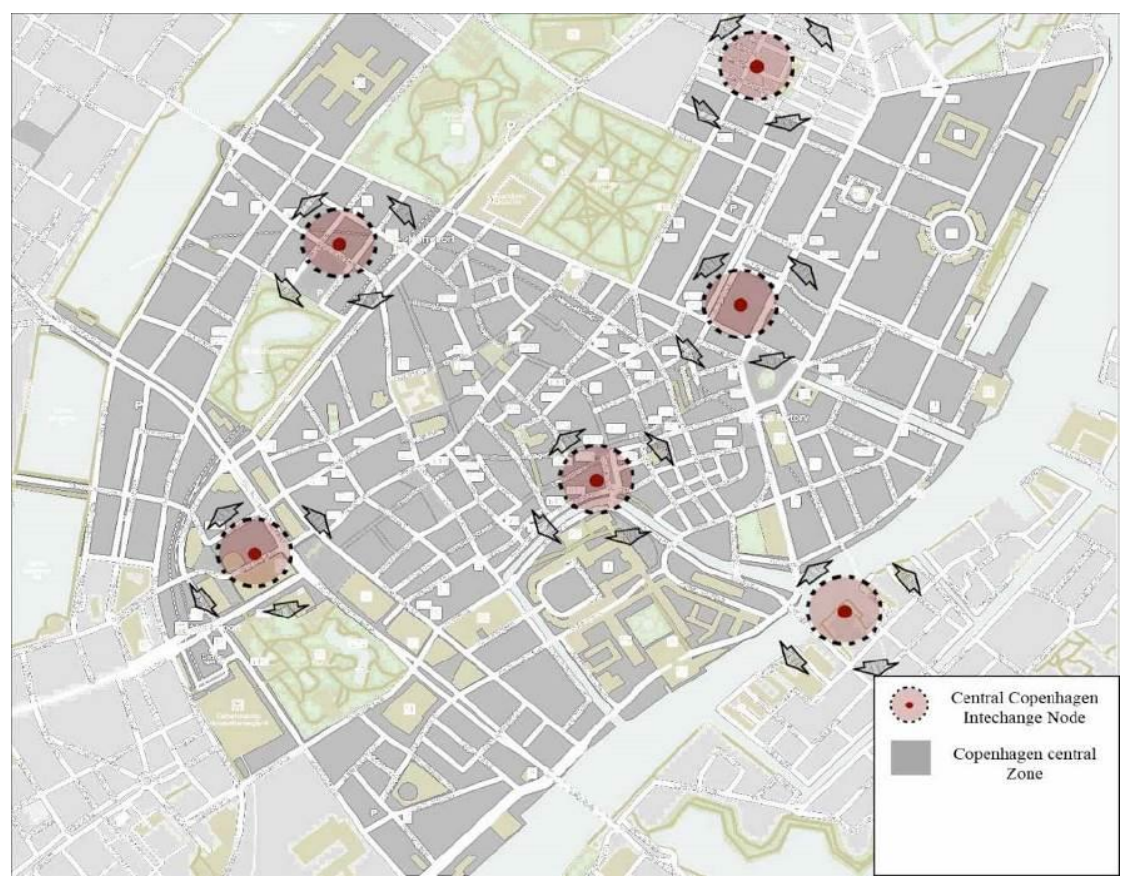

Fig. 6 Examples of public transport interchange nodes in Copenhagen.

Source: (Ole, 2006) [19] 


\subsection{Urban Design Policies:}

The main objective was to encourage people to walk, to cycle and use the city more as well as providing more sustainable environment.

\subsubsection{Walking Strategy}

The city did not encourage the use of cars in the downtown area, by making it difficult to drive and park. Better facilities for pedestrians to sit and spend time were created, as well as more tree and plant guards, more space at side roads junctions. These measures were highly beneficial for cyclists and pedestrians. As a result, the number of cycling and walking trips increased, people felt safer, and noise decreased, and buses time punctuality was much better. [20]

\begin{tabular}{|c|c|c|c|}
\hline \multicolumn{4}{|c|}{ The walking strategy aimed to: } \\
\hline $\begin{array}{l}\text { Convert streets } \\
\text { into pedestrian } \\
\text { thoroughfares }\end{array}$ & $\begin{array}{lr}\text { Reduce } & \text { traffic } \\
\text { and } & \text { parking } \\
\text { gradually }\end{array}$ & $\begin{array}{l}\text { Turn parking lots } \\
\text { into public } \\
\text { squares }\end{array}$ & $\begin{array}{l}\text { Honour the } \\
\text { human scale }\end{array}$ \\
\hline
\end{tabular}

Fig. 7 Aims of walking strategy in Copenhagen Streets. Source: the researchers
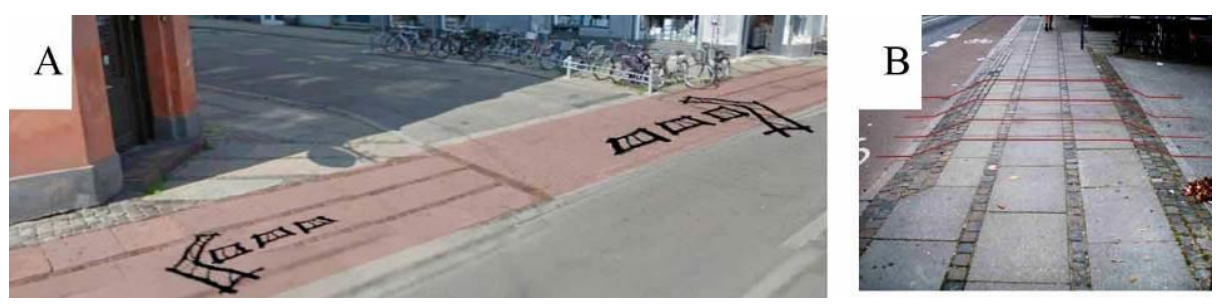

Fig. 8 a)Pedestrian crossing paving at Norrebrogade street to accentuate the physical continuity. Source: google Earth street view; b) Local Road Threshold Treatments, Norrebrogade Copenhagen, Source: (Kollmorgen, 2008); Edited by Researcher

\subsection{2 cycling Strategy}

More cycle parking facilities were provided. As well as establishing new bike lanes and extending existing ones. Cycle lanes were widened to guarantee the cyclist comfort. According to (Jensen, 2009), the cycling policy was set to reach certain goals which are: a) Increase the proportion of people cycling to workplaces in Copenhagen from $34 \%$ to $40 \%$, b) Decrease cyclist risk of serious injury or death by $50 \%$, c) Increase the proportion of Copenhagen cyclists who feel safe cycling from $57 \%$ to $80 \%$, d) Increase cyclist travelling speed by $10 \%$ and e) Improve cyclist comfort so that $95 \%$ of cycle track surfaces are satisfactory. 


\section{Case Study: Safeya Zaghloul Street in The City Centre of Alexandria}

The second half of the twentieth century has witnessed a great dependence on private cars in Alexandria city centre. People prefer using private cars even for the shortest distance in the city centre because of the absence of appropriate public transportation.

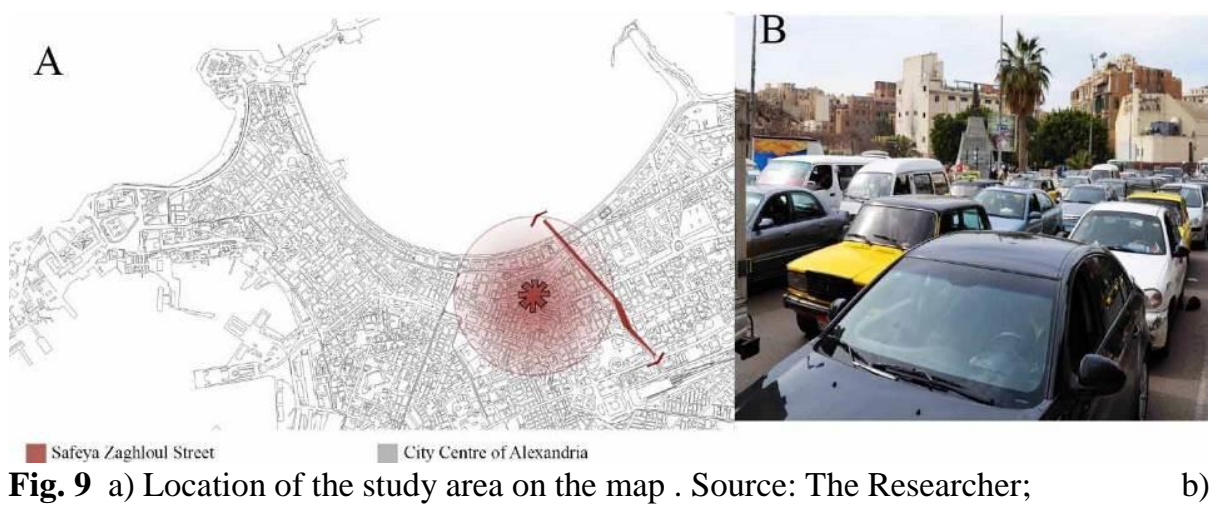

Fig. 9 a) Location of the study area on the map . Source: The Researcher;
Congested Sefeya Zaghloul Street during the rush hour. Source: The Researcher

Safeya Zaghloul Street is one of the most vital streets in Alexandria, almost every day till midnight; this is due to its commercial nature. People from all over the city come to this street for the purpose of shopping. Since Safeya Zaghloul is almost a commercial street, its storefronts are playing an important role in its vitality.

The street begins with the first node; Saad Zaghloul Square, which is used as a vital parking area as well as a public garden. Then it goes through the Raml station which as an important node for public transportation. After that, it goes through the Ancient Roman Village, which is considered as important points of attraction for visitors and tourists. Then, it ends up with Misr Railway Station, which has a closed, and old underground garage.

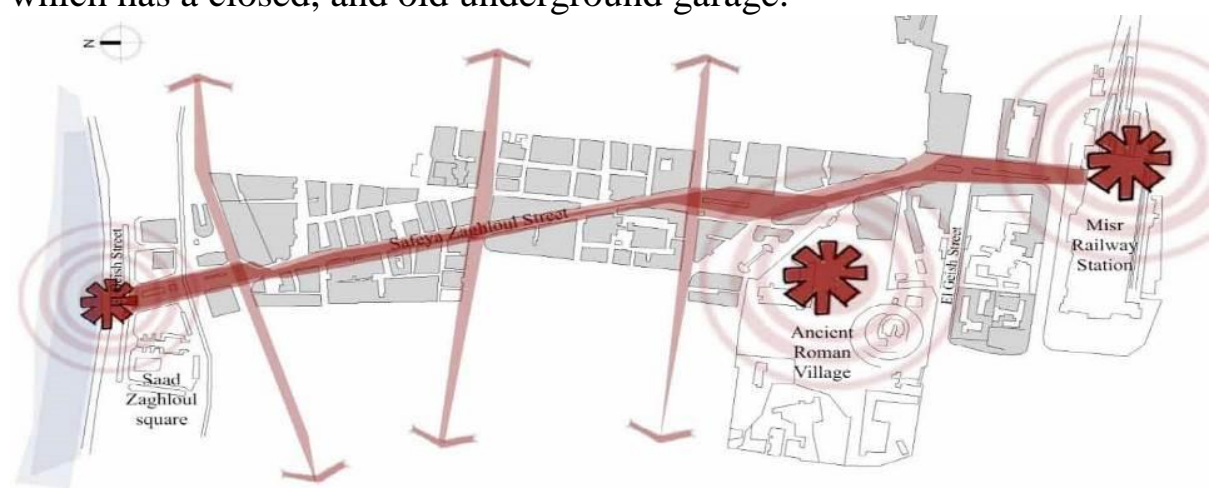

Fig. 10 Important nodes of Safeya Zaghloul Street.; Source: The Researcher

\subsection{Transportation planning policies to be applied in Safeya Zaghloul Street:}

All the previous potentials can be used to encourage pedestrian and public transportation usage to enhance the urban fabric of the studied area. For instance the government can apply the cordon charging that force private cars 
to use the public parking. And then, they could have the choice either, by using public transportation or enjoying the walkability activity through this Vital Street. Bicycle parking could also be provided within the area in order to encourage bicycle riding as a sustainable mean of transportation.

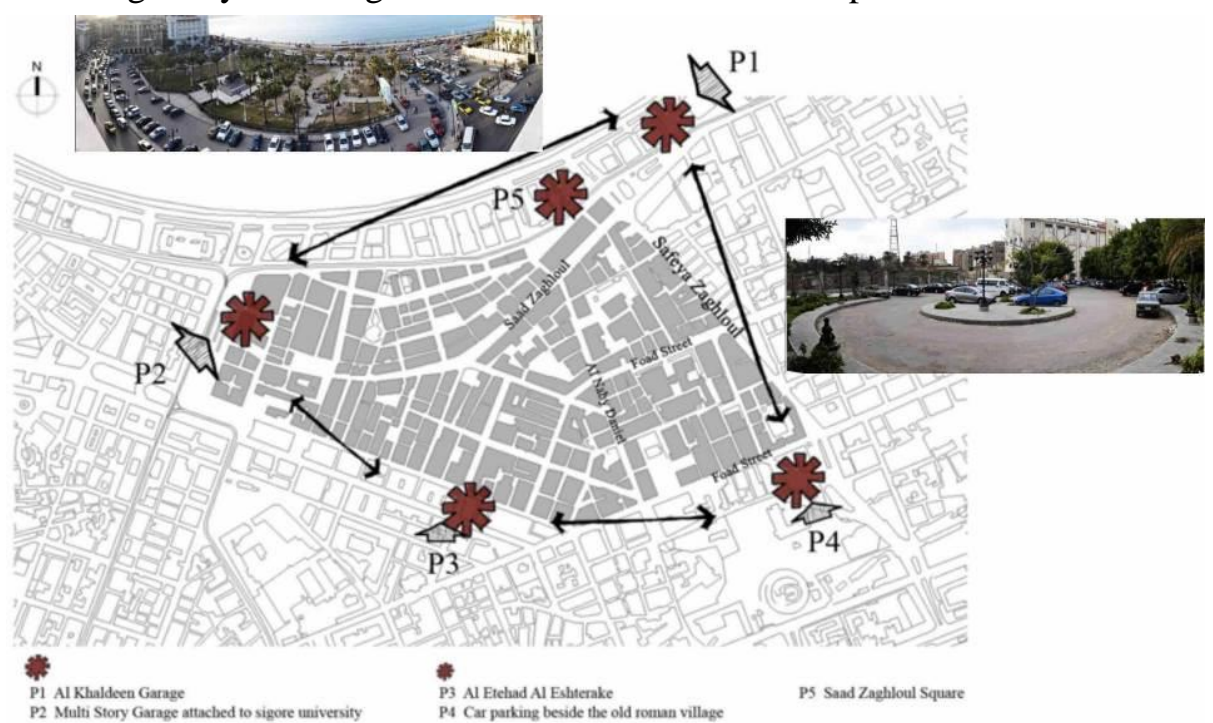

Fig. 11 Five main parking areas surrounding the study zone.; Source: The Researcher

\subsection{Urban design policies to be applied in Safeya Zaghloul Street:}

\subsubsection{Walkability in Safeya Zaghloul Street:}

In order to encourage walkability as a main alternative for car dependency in in Safeya Zaghloul Street, it is very important to enrich the pedestrian facilities in order to enhance the walkability services within the urban context.

\section{Improving the conviviality (safety) of Safeya Zaghloul Street}

Uncovered manhole sample should be covered.

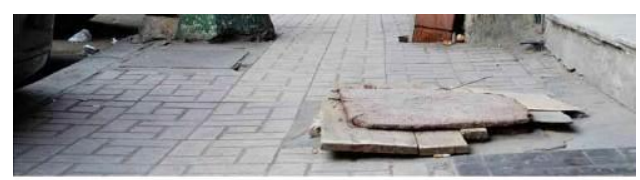

Pedestrian crossings need to be maintained and to be clearer through periodical painting.

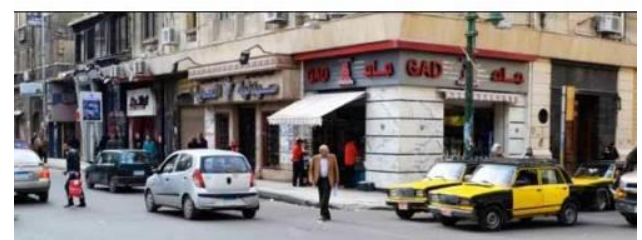

Fig. 12 negative points that should be improved to provide safe pedestrian street; Source: The Researcher 


\section{Improving the Street Furniture in Safeya Zaghloul Street}

Street lighting the majority are down lighting to prevent glare and unnecessary light pollution. it was noticed that these poles were maintained in most of the street but there is a distance between these poles, which does not guarantee adequate overall lighting level.

\section{Public Seat}

There is almost no seat found to serve pedestrians on both sides of the street, which is considered a week point in such a pedestrian environment. The street is too long for elder people, that is why public seats are needed every now and then as a rest. The only area that has marble seats and most of them are unfortunately stolen is Ismael Basha square. This square has a great potential to be a vital public space.

\section{Paving materials}

The whole sidewalk on both sides of the street is paved with cement.

Except for the plaza of Ismael Basha Square, which is paved with granite and separated from the sidewalk with a one meter border of white marble. The pavment is divided into three parts that differ in color.

The width of pedestrian sidewalk all over the street is unequal, at some parts it is more than three meters wide while at other parts it is only a meter wide and some parts are not paved at all.
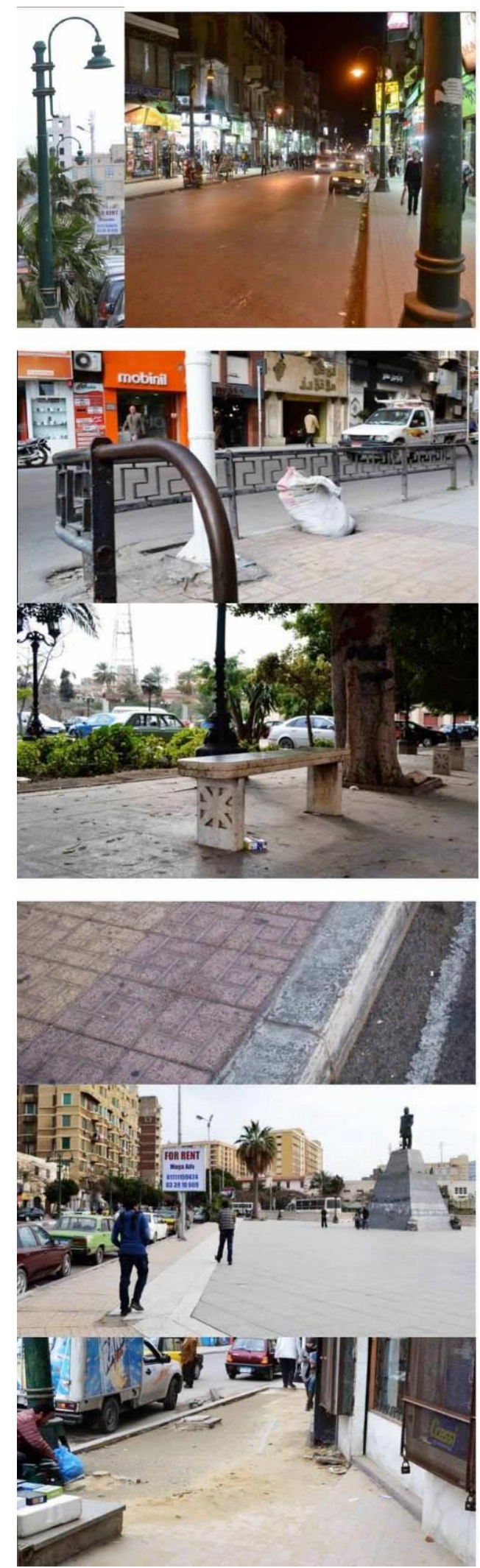


\section{Improving the Street Furniture in Safeya Zaghloul Street}

\section{Landscape elements}

Trees are limited with respect to such open spaces especially at the intersection of Safeya Zaghloul Street with Foad Street; these streets would have the potential for street trees where pavements are relatively wide. The only planted area is the median between Foad Street and Ismael Basha Street.

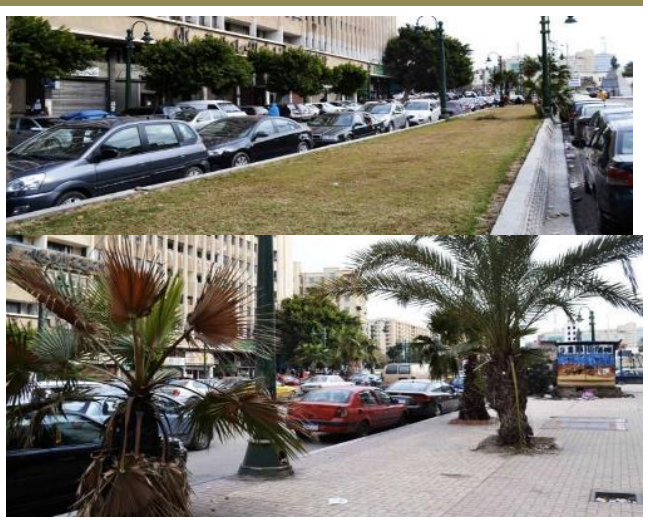

Fig. 13 Street furniture that should be improved to provide more convenient pedestrian street.; Source: The Researcher

Fig. 14 Landscape elements should be improved to provide more convenient pedestrian street; Source: The Researcher

Fig. 15 Cars prioritized over pedestrians.; Source: The Researcher

\subsection{2 cycling Strategy}

It is notable that road system in Alexandria in general was never been designed for cycling. The road system has not been designed for mixing the unprotected lightweight and slower road users, such as cyclists with heavy and high velocity vehicles. However, there is some design measures that can be taken to decrease traffic speeds where bicycle use or demand is potentially high; roads should be widened to include bike lanes if the travel speeds and volumes on the roadway are high.

Improving the con

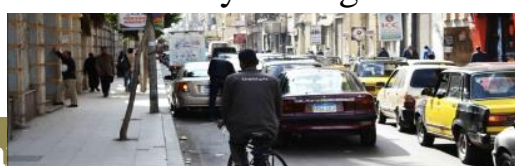

The fence should bc As it is totally affecting the continuity of pedestrian sidewalks; it also emphasises the dominance of cars. Pedestrian traffic light should also be provided

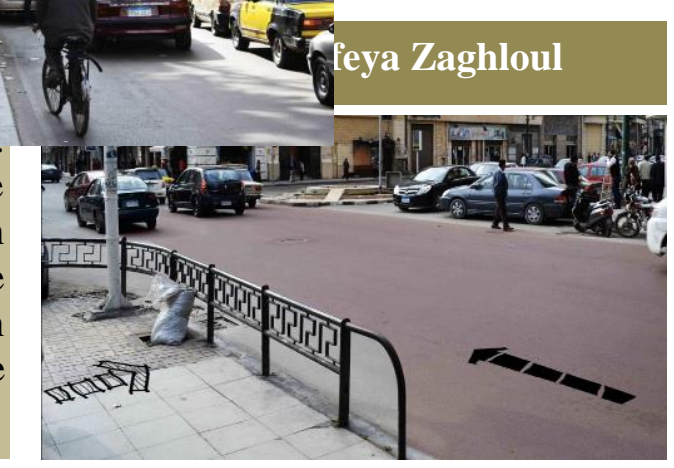

Fig. 16 type of cycling routes in the study area; Source: The Researcher

\section{Conclusion}

Car dependency in the congested city centre is becoming a major problem affecting the urban environment as well as human health. The analysis of a car 
free city centre such as Copenhagen city has identified the importance of contributing walking and other modes of transport like cycling on peopl's daily life, and how policies like congestion charging could lead to dramatic reductions in car dependency in city centres. Benefiting from this successful example policy maker in Egypt can apply the used strategies in order to achieve car free zones in the congested city centre. As a short term Strategy, walking conditions for Safeya Zaghloul Street should be enhanced to encourage people of all ages to walk more. Other measurements that affect pedestrian safety should also be considered. Cordon charging could be applied by taking advantage of the five parking areas located around the zone of Safeya Zaghloul Street. This policy will prohibit vehicles access and the presence of the parking areas will give car users the chance to leave their cars. At this point, the government could increase the number and the quality of public transport, which covers the area. Cycling and integrated transport interchange is long term strategies that need either change in mobility culture or massive investments. Also, policy makers could introduce a cycling hire system with bicycle parking.

\section{References}

1. Kenworthy, J., \& Newman, P.; Sustainability and cities: Overcoming automobile dependence, Washington: Island Press, 1999

2. Vigar, G.; The politics of mobility. Transport, the environment and public policy. London: Spon Press, 2002

3. Michon, J., \& Vlek, C.; Why we should and how we could decrease the use of motor vehicles in the near future. International Association of Traffic and Safety Sciences., 1992

4. Larkin, M.; Can cities be designed to fight obesity. The Lancet, 1046-1047, 2003

5. Appleyard, D.; Livable streets. Journal of the American Institute of Planning ,216224, 1981

6. European Conference of Ministers of Transport [ECMT], Annual Report 2002.

7. Hartmut Topp, T. P. ; Car-free city centres. Transportation , 231-247, 1994

8. KumKum, D., \& Israr, A.; Carpooling: A Step To Reduce Congestion (A Case Study of Delhi). Delhi: International Association of Engineers, 2007

9. Millard, A.; Car-Sharing:Where And How It Succeeds. Washington, D.C.: Transportation Research Board, 2005

10. Hawkins, P. ; Creating a local parking strategy that works. london: steer davies gleave, 2011

11. Bénard, V.; Innovative Demand Management Strategies:Road Pricing Schemes. (Stockholm),: Niches, 2003

12. Schönfelder, S., \& Axhausen, K. W.; The impact of transport on social exclusion processes with specific emphasis on road user charging. Transport Policy, 321338, 2003

13. Commission, E., Green Paper on The Impact of Transport on the Environment - a community strategy for sustainable mobility. Bruxelles, 1992

14. Hillman, M.; Cycling. Towards Health and Safety. Oxford: British Medical Association, 1992

15. Andrew, A.; Pedestrian Priority Addressing Car Dependency - Purposes and Benefits. Australia: University of South Australia,2011

16. WP2, P.; Description Of Urban And Mobility Context In Copenhagen . copenhagen: PROGRESS Project 2000, 2001

17. Kommune, K.; Impact of Copenhagen's Parking Strategy. Copenhagen: The Technical and Eenvironmental Administration, 2009 
18. Rudlin, D.; Study Tour Copenhagen. London: URBED, 2012

19. Ole, R.; How bicycles can become an efficient. Copenhagen: Geography department, 2006

20. Gerike, R., \& München, T.; Infrastructure for walking and cycling . Copenhagen: corpus, 201 